RESEARCH PAPER

\title{
Perceptions of nurses, families, and residents in nursing homes concerning residents' needs
}

\author{
Merav Ben Natan RN PhD Student \\ Lecturer at Pat Matthews Academic School of Nursing, Hillel Yaffe Medical Center, Hadera, Israel
}

Accepted for publication November 2007

Ben Natan M. International Journal of Nursing Practice 2008; 14: 195-199

\begin{abstract}
Perceptions of nurses, families, and residents in nursing homes concerning residents' needs
\end{abstract}
This study examined the congruence between needs identified as significant by older adults in comparison with caregivers (nurses) and elders' families. The study involved 44 patients, 94 nurses and 44 families from the Shoham Geriatric Center in Pardes Hanna, Israel. The findings are based on data gathered through questionnaires distributed at the nursing home. The findings indicate a discrepancy between residents' needs as identified by the staff, the families and the elderly residents themselves. An analysis based on primary needs showed that in comparison with the residents and their families, the nurses attributed greater significance to values and personal outlook of the residents, provision of proficient physical care, skilled mental support, social life and institutional requirements. Families attributed the most significance to the provision of information and family involvement, and in contrast, according to the residents, the most important area was skilled mental/emotional support. Also discussed are the research and practical implications of these findings.

Key words: families, needs, nurses, nursing home, residents.

\section{INTRODUCTION}

The number of elderly people in Israel (65+) is increasing at a previously unknown rate. Since 1955 , this population has increased by $7.7 \%$; although, the general population has multiplied by $3.7 \%$. The elderly population is rising persistently because of the increase in life expectancy in Israel. ${ }^{1}$

Long-term geriatric nursing care must reflect the needs and preferences of elderly residents and their families in order to promote quality of care. ${ }^{2}$ Certain needs are routinely provided by nursing homes; however, sometimes, in order to fulfil a need, the nursing staff must be aware of the needs of the residents and of their families. Presented in this paper are the findings of a study examining the

Correspondence: Merav Ben Natan, Pat Matthews Academic School of Nursing, Hillel Yaffe Medical Center, Hadera, Israel.Email: meraav@ hy.health.gov.il needs of elderly residents at a nursing home according to their own perception and in comparison with the perceptions of their families and the nursing staff.

\section{LITERATURE REVIEW}

The needs of elderly persons residing in nursing homes are varied and connected to their health problems, the manner in which they experience their illnesses and their needs when healthy. ${ }^{3}$ Various definitions are suggested to define the concept of needs of elderly people. Von Wright ${ }^{4}$ defined a need as an element which a person requires and cannot do without. He claimed that needs are broadly defined and that residents might be harmed by a reduction of this definition. Lindrooth et al. ${ }^{5}$ claimed that the needs of elderly residents vary according to their health condition, age, gender and culture.

Various studies indicate that the most significant need for elderly nursing home residents is the need to trust the 
nursing and medical staff. ${ }^{6,7}$ When residents are admitted to a nursing home they expect to acquire trust in the caregiving staff. Residents usually expect the nursing and medical staff to provide for their needs, based on the degree of trust that develops between them. Situations, in which the staff do not respond appropriately to significant needs as perceived by residents, such as insufficient or inaccurate information, violation of the resident's right to privacy or the right to make independent decisions or to autonomy, might cause residents to mistrust the staff. ${ }^{8}$ Santo-Novak ${ }^{7}$ studied the care expectations of elderly residents of a nursing home for a period of up to 2 years. The research findings indicated that residents expected their need for adequate communications to be fulfilled.

Compared with needs identified as significant by residents, Li et al. ${ }^{6}$ found that residents' families also perceived the provision of information concerning the residents' condition and the care provided as significant. In addition, the study found that cleanliness of the nursing home and of the residents' rooms was the family members' second primary need. In contrast to the findings of the above mentioned study, Boumans et al. ${ }^{9}$ claimed that families' most significant need is personal attention showed to the residents. Families who felt that the nursing staff treated their parents warmly and respectfully expressed the highest degree of satisfaction towards the nursing home.

Studies that examined the opinion of the caregiving staff, particularly nurses, concerning the needs of elderly residents, indicate that nurses emphasize the need for skilled physical care and emotional support. ${ }^{3}$ Packham ${ }^{10}$ found that nurses rank institutional needs, such as providing residents with information about institutional requirements, as most significant. It is assumed that the discrepancy of needs identified by residents, families and nursing staff, is related to the specific characteristics and individual viewpoints of each group.

In light of this review, the research hypotheses for this study were:

1. Perceptions by the staff and by residents' families concerning the needs of elderly nursing home residents differ from the residents' own perception of their needs.

2. There is a correlation between characteristics of the nurses and their perception of the needs of elderly nursing home residents.

3. There is a correlation between residents' and families' characteristics and their perception of the needs of elderly nursing home residents.

\section{RESEARCH METHOD Research tools}

This study made use of a questionnaire designed by Ryden et al. ${ }^{2}$ This questionnaire is a satisfaction instrument specifically designed for use with nursing home residents. It was modified from satisfaction to needs of nursing home residents. The questionnaire is comprised of 35 items with answers ranked on a four-step Likert scale designed to measure agreement concerning residents' needs. Responses range from: (4) I agree very much to (1) I disagree very much. The questionnaire takes approximately 20 min to complete. High scores reflect agreement regarding significant needs of geriatric-centred residents; low scores reflect disagreement.

The questionnaire presents five needs identified by the literature review, and all are significant needs to nursing home residents:

- Attention to values and personal outlook;

- Provision of information;

- Skilled physical care;

- Social life;

- Institutional standards.

Reliability for the questionnaire is $\alpha$-Cronbach $=0.81$, after modification of the questionnaire.

\section{Research population}

The total number of residents in the Shoham Nursing Home in Pardes Hanna is 670. Of these, 90 residents need assistance and live in the 'Assisted Living Units.' The questionnaire was distributed to 44 residents in the 'Assisted Living Units' and their families, and to 94 of the resident's nurses who had 1-year working experience. Elderly residents suffering from cognitive impairment or who could not answer the questionnaire for health reasons or because of language difficulties were not included in the study. There was no minimum length of stay required for residents, but only nurses with 1 -year working experience were included.

\section{Ethical considerations}

The head nurse of Shoham gave permission to perform the study and informed the relevant staff about it in a staff meeting.

The head nurse of each assisted living unit, who was not involved in the study, invited qualifying residents, their families and nurses to participate. The investigator was not an employee of the nursing home. The voluntary 
nature of participation was stressed, as was confidentiality. The research was approved by the Ethics Research Committee of the nursing home. In the introduction to the questionnaire, it was clearly stated that its purpose was to improve the care of the residents.

\section{Procedure}

A one specific day was chosen to perform the study in each of the three assisted living units. The head nurse of Shoham informed the participating residents and their families where and when the study would take place. Verbal and written information was provided by the investigator. The residents and the families were asked to complete the questionnaires. A list of all 200 nurses at Shoham was obtained and all were invited to participate in the study. A letter was sent to each currently employed nurse. The sample of the nurses was a convenient sampling. All nurses who were willing to participate and who volunteered their time were invited to join the study. Ninety-four wished to participate.

\section{Statistical analysis}

The questionnaire includes 35 items of resident needs. For each item the average was calculated for each individual included in the study. A high average indicates the special significance assigned to each item. Each individual identified what to him were the five most significant items. The items were separated into five areas. In each area the validity of the measurement was examined. The reliability was sufficient over 0.5 . Using theoretical statistical methodologies (frequency, mean and SD), the items were distributed according to the research variables in each one of the study groups (nurses, residents and their families). A Pearson correlation to continuous quantitative variables was used to examine relationships among: age, number of children and length of residency in the unit. A $t$-test was used to examine differences according to gender and units. ANOva was used to examine differences according to education, religion and marital status.

\section{Background Information}

The residents

The study included 44 residents from the assisted living units, of whom a high percentage was elderly $(75+)$. The mean age of the residents was 77.12 (SD 10.9); 7.3\% of them were aged 60 and younger, 19.5\% aged 61-70, $29.3 \%$ aged $71-80,36.6 \%$ aged $91-90$, and $7.3 \%$ over 90. The majority of the residents $(59.5 \%)$ were women.
Most of the men (90\%) were married; most of the women were widows (80\%); $60.6 \%$ of the residents had at least two children. Most of the residents had received elementary education (46.2\%). Most of them were Jewish (97.5\%). Seventy-five per cent of the residents had been living at the institution for over 2 years and only $25 \%$ had been there for less than 2 years.

\section{The families}

The majority of the 44 interviewees were daughters of the (44) residents. Their mean age was 55.4 (SD 14.2); $12.5 \%$ of the visiting relatives were aged 40 and younger, $27.1 \%$ aged $41-50,33.3 \%$ aged $51-60,14.6 \%$ aged 61-70, and $12.5 \%$ over 70 . Most were married and parents of 3-4 children. They had a secondary school level of education (48.9\%) and most of them were secular; $54.8 \%$ of the interviewees visited the residents one to two times a week, $23.8 \%$ visited three to four times a week, and only $21.4 \%$ visited five times a week or more.

\section{The caregivers (nurses)}

Ninety-four nurses participated in the study. Their mean age was 40 . Their age range was as follows: 40 and younger-38.6\%, 41-50-42\% and over 50-19.3\%. Most of the nurses were married women with 3-4 children.

The majority of the nurses were practical nurses $(\sim 70 \%)$, as presented in Table 1. A licensed practical nurse in Israel is equivalent to a licensed practical nurse in the United States. It includes 2 years of study and in Israel, practical nursing programs last 2 years and includes both classroom study and supervised clinical practice (patient care). Of the 30\% registered nurses, $7.9 \%$ were registered nurses with a diploma, 4.5\% registered nurses with bachelor's degree, 9.5\% registered nurses with

Table 1 Distribution of nurses' training $(n=94)$

\begin{tabular}{lr} 
Nurses' training & $\%$ \\
\hline Practical nurse & 69.8 \\
Registered nurse & 7.9 \\
Registered nurse with bachelor degree & 4.5 \\
Registered nurse with specialized course & 9.5 \\
Registered nurse specialized course + bachelor degree & 6.3 \\
Registered nurse with master's degree & 1.6 \\
\hline
\end{tabular}


specialized course, $6.3 \%$ registered nurses with specialized course + bachelor's degree, and 1.6\% registered nurses with master's degree. Most of the nurses had professional seniority of 11-20 years. Much of their professional experience had been acquired at the Shoham centre.

\section{Research findings}

Residents

Residents $(n=44)$ ranked the following items highest: independence, developing trust towards the nursing staff, the possibility of family visits and a clean environment. Nurses $(n=94)$ ranked the following items highest: privacy, a warm welcome to the ward, establishing trust towards the nursing staff and safety precautions. Families $(n=44)$ ranked the following items highest: receiving information about the residents' medical condition, provision of precise information, trust towards the nursing, a clean environment and using proper equipment for treatments.

Hypothesis 1, that is, 'perceptions by the staff and by residents' families concerning the needs of elderly nursing home residents differ from the residents' own perception of their needs', is therefore supported.

\section{Nurses}

Nurses attributed the greatest significance to values and personal outlook, provision of skilled physical care, mental support. The connection between nurse characteristics and their perception of resident needs was examined by a statistical examination as described in the data analysis section. Older nurses tended to attribute greater significance to the provision of physical care $(r=0.244$, $P<0.05)$. Thorough inquiries indicated that older nurses are mostly practical nurses. Hypothesis 2 states: 'there is a correlation between characteristics of the nurses and their perception of the needs of elderly nursing home residents'. Regarding the age of the nurses the hypothesis is supported. The data indicate that nurses' perceptions of resident needs varied according to the age of the nurses.

\section{Families}

Families attributed much significance to the provision of information and family involvement. The longer the residents lived at Shoham, the less need the families saw for information $(r=-0.334, P<0.05)$ and family involvement $(r=-0.326, P<0.05)$. Hypothesis 3 states: 'there is a correlation between families' characteristics and their perception of the needs of elderly nursing home residents'. This hypothesis was supported only by the characteristic of involvement.

\section{Residents}

The most significant need as perceived by the residents themselves was skilled mental/emotional support. Residents with large families (many children) attributed less significance to social life at the nursing home $(r=-0.468, P<0.01)$. Hypothesis 3 stated 'there is a correlation between residents' characteristics and their perception of the needs of elderly nursing home residents'. This hypothesis is supported only by the characteristic of family size.

\section{DISCUSSION}

The study findings indicate that there is almost no correlation between the needs identified as significant by the residents and the needs identified by the nursing staff and the families. However, when comparing the primary needs mentioned one need is conspicuous in that it is significant for all, residents, nurses and families - the need to be able to trust the nursing staff. This need was also identified in most studies dealing with the needs of residents in nursing homes and general hospitals. ${ }^{11,12}$ When residents acquire trust for their caregivers they are also confident that their other needs will be fulfilled, both on a personal level and on the social or institutional level. Ryden et al. ${ }^{2}$ proved that residents who put significant trust in their caregivers are unwilling to report dissatisfaction with their care.

Families ranked the provision of information as most significant. Provision of information enables families and residents to participate in making therapeutic decisions concerning the residents. ${ }^{13}$ Residents also ranked the communication aspect as the most significant for them, but in their case communication for skilled mental/ emotional support was more important than communication to provide information. Residents are interested in speaking to someone who will listen, understand and support them emotionally. ${ }^{14}$ De Veer and Kerkstra ${ }^{11}$ stated that for elderly nursing home residents a very significant aspect is the staff's openness towards them and the possibility of supporting all their mental/emotional needs, particularly coping with long-term residence in an institution that is not their home.

Nurses also stated that the need for mental/emotional support of the residents is a significant need and ranked it 
as third on their list of significant needs; however, in their opinion the need for skilled physical care received a higher priority. Additional research discussed the issue of nurses, particularly practical nurses, who insist on naming the provision of physical care as a primary need. ${ }^{15}$ This difference might stem from the fact that practical nurses receive less training. Essentially the skills they acquire are directed at the provision of skilled physical care and they are not expected to acquire tools for providing the residents with mental/emotional support.

\section{SUMMARY}

Identifying the needs of nursing home residents is crucial to the quality of life of these elderly people. In light of the study results, which indicate a lack of correlation between needs perceived by the residents as significant, compared with those seen as essential by their families and/or by the nurses, it is highly recommended to formulate an institutional procedure using a questionnaire that can identify the needs of residents as the residents themselves see them and as their families see them at suitable points during the residents' stay. This questionnaire could be distributed to residents and their families twice during their first year. It is critical to inform the nursing and medical staff and the management of the nursing home regarding needs identified as significant and to coordinate residents' care accordingly.

\section{REFERENCES}

1 Be'er S. 65 year olds: Facts and Numbers. Jerusalem: A National Information Bank Resource to the Design in the Old Age Section. Jerusalem: The Myers-JDC-Brookdale Institute, 2003.

2 Ryden MB, Gross CR, Savik K, et al. Development of a measure of resident satisfaction with the nursing home. Research in Nursing and Health 2000; 23: 237-245.
3 Hallstrom I, Elander G. A comparison of patient needs as ranked by patients and nurses. Scandinavian Journal of Caring Science 2001; 15: 228-234.

4 Von Wright H. Needs. The Journal of Philosophy 1982; 3: $1-12$.

5 Lindrooth RC, Hoerger TJ, Norton EC. Expectations among the elderly about nursing home entry. Health Services Research 2000; 35: 1181-1202.

6 Li H, Stewart BJ, Archbold PG, Dodd MJ, Dibble SL. Family caregiving skill: Development of the concept. Research in Nursing Health 2000; 23: 191-203.

7 Santo-Novak DA. Older adults' descriptions of their role expectations of nursing. Journal of Gerontology Nursing 1997; 23: 32-40.

8 Bower KN, Ilten TB, Williams H. Meeting communication needs: Topics of talk in the nursing home. Journal of Psychosocial Nursing and Mental Health Services 2005; 43: 38-45.

9 Boumans N, Berkhout A, Landeweerd A. Effects of resident-oriented care on quality of care, wellbeing and satisfaction with care. Scandinavian Journal of Caring Science 2005; 19: 240-250.

10 Packham CJ. Needs of elderly people in residential homes: Comparison of records held by carers and general practitioners. Journal of Re Colling General Practice 1989; 39: 335337.

11 De Veer JE, Kerkstra A. Feeling at home in nursing homes. Journal of Advanced Nursing 2000; 35: 427-434.

12 Grau L, Chandler B, Saunders C. Nursing home residents' perceptions of the quality of their care. Journal of Psychosocial Nursing and Mental Health Services 1995; 33: $34-41$.

13 Williams KI, Ilten TB, Bower H. Meeting communication needs: Topics of talk in the nursing home. Journal of Psychosocial Nursing and Mental Health Services 2005; 43: 38-45.

14 Rantz MJ, Zwygart-Stauffacher M, et al. Nursing home care uality: A multidimensional theoretical model integrating the views of consumers and providers. Journal of Nursing Care Quality 1999; 14: 16-37.

15 Greenhalgh J, Vanhanen L, Kyngäs H. Nurse caring behaviours. Journal of Advanced Nursing 1998; 27: 927-932. 